International Journal of Pure and Applied Mathematics

Volume 106 No. 3 2016, 923-936

ISSN: 1311-8080 (printed version); ISSN: 1314-3395 (on-line version)

url: http://www.ijpam.eu

doi: 10.12732/ijpam.v106i3.17

\title{
CONNECTIVITY IN THE CASE OF AN IDEMPOTENT PRETOPOLOGY
}

\author{
Monique Dalud-Vincent ${ }^{1}$, Michel Lamure ${ }^{2}$ \\ ${ }^{1}$ MEPS - Max Weber Center \\ FASSP \\ University Lyon 2 \\ 5 Avenue Pierre Mendès-France \\ 69676 Bron cedex, FRANCE \\ ${ }^{2}$ Professor emeritus \\ University Lyon 1, FRANCE
}

\begin{abstract}
This work focuses on connectivity in a pretopological space where the pseudoclosure mapping is an idempotent one.
\end{abstract}

AMS Subject Classification: 54A05, 54B05, 54B15

Key Words: graph, pretopology, connectivity, idempotent pseudoclosure

\section{Introduction}

We already illustrated how pretopology generalizes both graph theory and topology [4]. We also established links between matroids and pretopology as well as between hypergraphs and pretopology [6].

In this paper, we present results concerning strong connectivity [4] and connectivity [7] in the case of a pretopology defined by an idempotent pseudoclosure (we now say an idempotent pretopology).

Received: December 10, 2015

Published: March 2, 2016
(C) 2016 Academic Publications, Ltd.

url: www.acadpubl.eu 


\section{Different Types of Pretopological Spaces, see [1] [2] [3] [4]}

Definition 1. Let $X$ be a non empty set. $P(X)$ denotes the family of subsets of $\mathrm{X}$. We call pseudoclosure on $\mathrm{X}$ any mapping $a$ from $\mathrm{P}(\mathrm{X})$ onto $\mathrm{P}(\mathrm{X})$ such as:

$$
\begin{gathered}
a(\varnothing)=\varnothing, \\
\forall \mathrm{A} \subset \mathrm{X}, \quad \mathrm{A} \subset a(\mathrm{~A}),
\end{gathered}
$$

$(\mathrm{X}, a)$ is then called pretopological space.

We can define 4 different types of pretopological spaces.

1. $(\mathrm{X}, a)$ is a $\mathrm{V}$-type pretopological space if and only if

$$
\forall \mathrm{A} \subset \mathrm{X}, \forall \mathrm{B} \subset \mathrm{X}, \mathrm{A} \subset \mathrm{B} \Rightarrow a(\mathrm{~A}) \subset a(\mathrm{~B})
$$

2. $(\mathrm{X}, a)$ is a $\mathrm{V}_{D^{-}}$-type pretopological space if and only if

$$
\forall \mathrm{A} \subset \mathrm{X}, \forall \mathrm{B} \subset \mathrm{X}, a(\mathrm{~A} \cup \mathrm{B})=a(\mathrm{~A}) \cup a(\mathrm{~B}) .
$$

3. $(\mathrm{X}, a)$ is a $\mathrm{V}_{S}$-type pretopological space if and only if

$$
\forall \mathrm{A} \subset \mathrm{X}, \quad a(A)=\bigcup_{x \in A} a(\{x\}) .
$$

4. (X, a) a $\mathrm{V}_{D}$-type pretopological space, is a topological space if and only if $\forall \mathrm{A} \subset \mathrm{X}, a(a(\mathrm{~A}))=a(\mathrm{~A})$.

Property 1. If $(X, a)$ is a $V_{S}$-type space then $(X, a)$ is a $V_{D}$-type space.

If $(X, a)$ is a $V_{D}$-type space then $(X, a)$ is a $V$-type space.

Example. Let $\mathrm{X}$ be a non empty set and $\mathrm{R}$ be a binary relationship defined on $\mathrm{X}$. Let $\mathrm{x} \in \mathrm{X}$. We note

$$
R(x)=\{y \in X / x R y\}
$$

and

$$
R^{-1}(x)=\{y \in X / y R x\} .
$$

The collateral pretopology, denoted $\mathrm{a}_{c}$, is defined by:

$$
\forall A \subset X, a_{c}(A)=\left\{x \in X / \forall y \in R^{-1}(x), R(y) \cap A \neq \varnothing\right\} \cup A .
$$

This pretopology is only a V-type one, see [9]. 
Definition 2. Let $(\mathrm{X}, a)$ be a $\mathrm{V}$-type pretopological space. Let $\mathrm{A} \subset \mathrm{X}$. $\mathrm{A}$ is a closed subset if and only if $a(\mathrm{~A})=\mathrm{A}$.

We note $\forall \mathrm{A} \subset \mathrm{X}, a^{0}(\mathrm{~A})=\mathrm{A}$ and $\forall \mathrm{n}, \mathrm{n} \geq 1, a^{n}(\mathrm{~A})=a(a)^{n-1}(\mathrm{~A})$.

We name closure of $\mathrm{A}$ the subset of $\mathrm{X}$, denoted $\mathrm{F}_{a}(\mathrm{~A})$, which is the smallest closed subset which contains A.

$\mathrm{F}^{\prime}{ }_{a}$, the inverse of the closure generated by $a$, is defined by:

$$
\forall A \subset X, F_{a}^{\prime}(A)=\left\{x \in X / F_{a}(\{x\}) \cap A \neq \varnothing\right\} .
$$

We note $a "=\mathrm{F}^{\prime}{ }_{a} \mathrm{~F}_{a}$ ( $a "$ is the composed of the mapping $\mathrm{F}^{\prime}{ }_{a}$ and $\left.\mathrm{F}_{a}\right)$ and $\mathrm{F}^{\prime}{ }_{a}$ the closure according to $a "$.

$a^{\prime}$ inverse of pseudoclosure $a$ is defined as follows:

$$
\forall A \subset X, a^{\prime}(A)=\{x \in X / a(\{x\}) \cap A \neq \varnothing\} .
$$

$a^{\prime}$ defines a pretopology on $\mathrm{X}$. We denote $\mathrm{F}_{a^{\prime}}$ the closure according to $a^{\prime}$ and $\mathrm{F}^{\prime} a^{\prime}$ the inverse of the closure according to $a^{\prime}$ (i.e. $\mathrm{F}_{a^{\prime}}$ ). We also denote $\mathrm{F}^{\prime \prime} a^{\prime}$ the closure according to $\left(a^{\prime}\right)^{\prime \prime}=\mathrm{F}^{\prime}{ }_{a^{\prime}} \mathrm{F}_{a^{\prime}}$.

Remark 1. If a is of V-type then $a^{n}, \mathrm{~F}_{a}, \mathrm{a}$ ", $\mathrm{F}^{\prime \prime}{ }_{a}$ also are of V-type and a' and $\mathrm{F}^{\prime}{ }_{a}$ are of $\mathrm{V}_{S}$-type. If $\mathrm{a}$ is of $\mathrm{V}_{S}$-type then $a^{n}, \mathrm{~F}_{a}, \mathrm{a}^{\prime}, \mathrm{F}^{\prime}{ }_{a}, \mathrm{a}^{\prime}, \mathrm{F}^{\prime}{ }_{a}$ are also $\mathrm{V}_{S}$-type.

Definition 3. Let (X,a) a V-type pretopological space. $a$ is idempotent if and only if $a^{2}=a$.

\section{Results Related to $(X, a)$ and $\left(X, a^{\prime}\right)$}

Proposition 1. Let (X,a) a V-type pretopological space. a is idempotent $\Leftrightarrow F_{a}=$ a.

Proof. Let us suppose that $a$ is idempotent.

Let $\mathrm{A} \subset \mathrm{X} . \mathrm{F}_{a}(\mathrm{~A})$ is the smallest closed subset including $\mathrm{A}$ (by definition of $\left.\mathrm{F}_{a}\right)$.

But, by idempotence of $a, a(\mathrm{~A})$ is a closed subset.

Let us prove that $a(\mathrm{~A})$ is the smallest closed subset including $\mathrm{A}$ :

If $a(\mathrm{~A})$ is not the smallest closed subset including $\mathrm{A}$, there exists $\mathrm{B}$ closed subset different of $a(\mathrm{~A})$ such as $\mathrm{A} \subset \mathrm{B}$ and $a(\mathrm{~B})=\mathrm{B}$. As $\mathrm{A} \subset \mathrm{B}$ and $a$ is of $\mathrm{V}$-type, we get $a(\mathrm{~A}) \subset a(\mathrm{~B})=\mathrm{B}$, which leads to a contradiction.

Then, we can say that $a(\mathrm{~A})$ is the smallest closed subset including $\mathrm{A}$ and $\mathrm{F}_{a}=a$. 
The converse is obvious.

Proposition 2. Let (X,a) a V-type pretopological space. If a is idempotent then a' is idempotent.

Proof. $\forall A \subset X$,

$$
\begin{aligned}
a^{\prime}(A) & \subset a^{\prime}\left(a^{\prime}(A)\right) \\
& \subset\left(a^{2}\right)^{\prime}(A) \quad(\text { see }[8]) \\
& \subset\left\{x \in X / a^{2}(\{x\}) \cap A \neq \varnothing\right\} \quad \text { (by definition) } \\
& \subset\{x \in X / a(\{x\}) \cap A \neq \varnothing\} \quad(a \text { is idempotent }) \\
& \subset a^{\prime}(A) \quad \text { (by definition). }
\end{aligned}
$$

So, we can say: $a^{\prime}(\mathrm{A})=a^{\prime}\left(a^{\prime}(\mathrm{A})\right)$.

Proposition 3. Let $(X, a)$ a $V$-type pretopological space. If a is idempotent then $F_{a}^{\prime}=a^{\prime}=F_{a^{\prime}}$.

Proof. If $a$ is idempotent then $a^{\prime}$ is idempotent (see Proposition 2).

Therefore, $\mathrm{F}_{a^{\prime}}=a^{\prime}$ (see Proposition 1).

On the other hand, $\forall \mathrm{A} \subset \mathrm{X}$,

$$
\begin{aligned}
F_{a}^{\prime}(A) & =\left\{y \in X / F_{a}(\{y\}) \cap A \neq \varnothing\right\} \\
& =\{y \in X / a(\{y\}) \cap A \neq \varnothing\} \quad(a \text { is idempotent }) \\
& =a^{\prime}(A) . \quad \text { (by definition) }
\end{aligned}
$$

Definition 4. Let $(\mathrm{X}, a)$ a $\mathrm{V}$-type pretopological space. Let $\mathrm{A} \subset \mathrm{X}$. We define the induced pretopology by $a$ on $\mathrm{A}$, denoted $a_{A}$, as follows:

$$
\forall C \subset A, \quad a_{A}(C)=a(C) \cap A .
$$

$\left(\mathrm{A}, a_{A}\right)$ (or more simply $\left.\mathrm{A}\right)$ is called a pretopological subspace of $(\mathrm{X}, a)$.

Proposition 4. Let (X,a) a $V$-type pretopological space with a idempotent. Let $A \subset X, A$ being a non empty set. We denote $F_{a A}$ the closure according to $\mathrm{a}_{A}, F^{\prime}{ }_{a A}$ the inverse of the closure according to $\mathrm{a}_{A}, F_{(a A)}$ the closure according to $\left(\mathrm{a}_{A}\right)^{\prime}$, and $\mathrm{F}_{\left(\mathrm{a}^{\prime}\right) A}$ the closure according to $\left(\mathrm{a}^{\prime}\right)_{A}$.

i. $\mathrm{F}_{a A}=\mathrm{a}_{A}$.

ii. $\mathrm{F}^{\prime}{ }_{a A}=\mathrm{F}_{(a A)^{\prime}}=\mathrm{F}_{\left(a^{\prime}\right) A}=\left(\mathrm{a}^{\prime}\right)_{A}=\left(\mathrm{a}_{A}\right)^{\prime}$.

Proof. i. Let $\mathrm{C} \subset \mathrm{A}$.

$$
a_{A}(C)=a(C) \cap A=F_{a}(C) \cap A,
$$


(see Proposition 1).

Moreover

$$
a_{A}(C) \subset F_{a A}(C) \subset F_{a}(C) \cap A
$$

(see [1]).

Therefore $\mathrm{F}_{a A}=a_{A}$.

ii. We have $\left(a_{A}\right)^{\prime}=\left(a^{\prime}\right)_{A}($ see $[8])$.

Then $\mathrm{F}_{(a A)^{\prime}}=\mathrm{F}_{\left(a^{\prime}\right) A}$.

On the other hand, whatever $\mathrm{C} \subset \mathrm{A}$,

$$
\begin{aligned}
F_{a A}^{\prime}(C) & =\left\{y \in A / F_{a A}(\{y\}) \cap C \neq \varnothing\right\} \quad \text { (by definition) } \\
& =\left\{y \in A / a_{A}(\{y\}) \cap C \neq \varnothing\right\} \quad \text { (Proposition 4-i) } \\
& =\left(a_{A}\right)^{\prime}(C) .
\end{aligned}
$$

At last, according to Proposition 4 -i, $a_{A}$ is idempotent.

Then $\left(a_{A}\right)^{\prime}$ is idempotent (see Proposition 2), and moreover $\left.\mathrm{F}_{(a A}\right)^{\prime}=\left(a_{A}\right)^{\prime}$, according to Proposition 1.

Ultimately, we get

$$
F_{a A}^{\prime}=F_{(a A)^{\prime}}=F_{\left(a^{\prime}\right) A}=\left(a^{\prime}\right)_{A}=\left(a_{A}\right)^{\prime} .
$$

\section{Subsets and Subspaces $x$-connected in $(X, a)$}

We shall speak about $\mathrm{x}$-connectivity to indicate one of the following types of connectivity:

Definition 5. (see [1] [6]) Let (X,a) a V-type pretopological space.

1- $(\mathrm{X}, a)$ is strongly connected if and only if $\forall \mathrm{C} \subset \mathrm{X}, \mathrm{C} \neq \varnothing, \mathrm{F}_{a}(\mathrm{C})=\mathrm{X}$.

2- $(\mathrm{X}, a)$ is connected if and only if $\forall \mathrm{C} \subset \mathrm{X}, \mathrm{C} \neq \varnothing, \mathrm{F}_{a}(\mathrm{C})=\mathrm{X}$ or $\mathrm{F}_{a}(\mathrm{X}$ $\left.\mathrm{F}_{a}(\mathrm{C})\right) \cap \mathrm{F}_{a}(\mathrm{C}) \neq \varnothing$.

Definition 6. (see [1] [6]) Let (X,a) a V-type pretopological space. Let A a non empty subset of $\mathrm{X}$. Let $\mathrm{B}$ a non empty subset of $\mathrm{X}$. There exists a path in $(\mathrm{X}, a)$ from $\mathrm{B}$ to $\mathrm{A}$ if and only if $\mathrm{B} \subset \mathrm{F}_{a}(\mathrm{~A})$. There exists a chain in $(\mathrm{X}, a)$ from $\mathrm{B}$ to $\mathrm{A}$ if and only if $\mathrm{B} \subset \mathrm{F}{ }_{a}(\mathrm{~A})$.

Proposition 5. (see [6]) Let (X,a) a V-type pretopological space.

i- If $\forall x \in X$ and $\forall y \in X$, there exists a chain in (X, a) from $\{y\}$ to $\{x\}$ then $(X, a)$ is connected. 
ii- $(X$, a $)$ is strongly connected $\Leftrightarrow \forall x \in X$ and $\forall y \in X$, there exists a path in $(X, a)$ from $\{y\}$ to $\{x\}$.

Proposition 6. (see [6]) Let $(X, a)$ a $V_{S}$-type pretopological space.

(X, a) is connected $\Leftrightarrow \forall x \in X$ and $\forall y \in X$, there exists a chain from $\{y\}$ to $\{x\}$ in $(X, a)$.

Property 2. (see [6]) Let (X,a) a V-type pretopological space. Let $x \in X$ and let $y \in X$.

$i$ - If there exists a sequence $x_{0} \ldots x_{n}$ of elements of $X$ such as $x_{0}=x, x_{n}=$ y with $\forall j=0, \ldots, n-1, x_{j+1} \in a\left(\left\{x_{j}\right\}\right)$ or $x_{j} \in a\left(\left\{x_{j+1}\right\}\right)$ then there exists $a$ chain in $(X, a)$ from $\{y\}$ to $\{x\}$.

ii- If there exists a sequence $x_{0} \ldots x_{n}$ of elements of $X$ such as $x_{0}=x, x_{n}=$ $y$ with $\forall j=0, \ldots, n-1, x_{j+1} \in a\left(\left\{x_{j}\right\}\right)$ then there exists a path in $(X, a)$ from $\{y\}$ to $\{x\}$.

Property 3. (see [6]) Let $(X, a)$ a $V_{S}$-type pretopological space. Let $x \in X$ and let $y \in X$.

$i$-There exists a chain in $(X, a)$ from $\{y\}$ to $\{x\} \Leftrightarrow$ there exists a sequence $x_{0} \ldots x_{n}$ of elements of $X$ such as $x_{0}=x, x_{n}=y$ with $\forall j=0, \ldots, n-1, x_{j+1} \in a$ $\left(\left\{x_{j}\right\}\right)$ or $x_{j} \in a\left(\left\{x_{j+1}\right\}\right)$.

ii-There exists a path in $(X, a)$ from $\{y\}$ to $\{x\} \Leftrightarrow$ there exists a sequence $x_{0} \ldots x_{n}$ of elements of $X$ such as $x_{0}=x, x_{n}=y$ with $\forall j=0, \ldots, n-1, x_{j+1} \in a$ $\left(\left\{x_{j}\right\}\right)$.

Property 4. (see [5]) Let (X,a) a $V_{S}$-type pretopological space. $\forall x \in X, \forall y \in X, x \in F^{\prime}{ }_{a}(\{y\}) \Leftrightarrow y \in F^{\prime}{ }_{a}(\{x\})$.

Définition 7. (see [1] [3]) Let (X,a) a V-type pretopological space. Let A $\subset \mathrm{X}, \mathrm{A}$ being a non empty set.

$\mathrm{A}$ is a pretopological subspace $\mathrm{x}$-connected of $(\mathrm{X}, a)$ if and only if $\left(\mathrm{A}, a_{A}\right)$, as a pretopological space, is x-connected.

$\left(\mathrm{A}, a_{A}\right)$ is a greatest $\mathrm{x}$-connected subspace of $(\mathrm{X}, a)$ if and only if $\left(\mathrm{A}, a_{A}\right)$ is a $\mathrm{X}$-connected subspace of $(\mathrm{X}, a)$ and $\forall \mathrm{B}, \mathrm{A} \subset \mathrm{B} \subset \mathrm{X}, \mathrm{A} \neq \mathrm{B},\left(\mathrm{B}, a_{B}\right)$ is not a X-connected subspace of $(\mathrm{X}, a)$.

Definition 8. (see [1]) Let $(\mathrm{X}, a)$ a V-type pretopological space. Let A $\subset$ $\mathrm{X}$, A being a non empty set. We note $\left(F_{a}\right)_{A}$ the closure obtained by restriction of the closure $F_{a}$ on A. $\left(F_{a}\right)_{A}$ is such as $\forall \mathrm{C} \subset \mathrm{A},\left(F_{a}\right)_{A}(\mathrm{C})=F_{a}(\mathrm{C}) \cap \mathrm{A}$.

$\mathrm{A}$ is a $\mathrm{X}$-connected subset of $(\mathrm{X}, a)$ if and only if $\mathrm{A}$, endowed with $\left(F_{a}\right)_{A}$, is $\mathrm{x}$-connected. We shall say that $\mathrm{A}$ is $\mathrm{x}$-connected to mean that $\mathrm{A}$ is a $\mathrm{X}$-connected subset of $(\mathrm{X}, a)$. 
$\mathrm{A}$ is a $\mathrm{X}$-connected component of $(\mathrm{X}, a)$ if and only if $\mathrm{A}$ is a $\mathrm{X}$-connected subset of $(\mathrm{X}, a)$ and $\forall \mathrm{B}, \mathrm{A} \subset \mathrm{B} \subset \mathrm{X}$ with $\mathrm{A} \neq \mathrm{B}, \mathrm{B}$ is not a $\mathrm{x}$-connected subset of $(\mathrm{X}, a)$.

Proposition 7. (see [1] [4]) Let (X, a) be a V-type pretopological space. Let $A \subset X$ with $A$ non empty.

$i$ - If $A$ is a x-connected subspace of $(X, a)$ then $A$ is a x-connected subset of $(X, a)$.

ii- If $a$ is an idempotent function, then:

$A$ is a $x$-connected subspace of $(X, a) \Leftrightarrow A$ is a $x$-connected subset of $(X$, a).

Proposition 8. (see [7]) Let $\left(X\right.$, a) be a $V_{s}$-type pretopological space. Let $\left\{U_{i}, i \in I\right\}$ a family of connected subsets of $(X, a)$ which is a partition of $X$.

$\forall i \in I, F{ }_{a}\left(U_{i}\right)$ is a connected component of $(X, a)$.

Proposition 9. Let $(X, a)$ be a $V$-type pretopological space.

Let $\left\{S_{i}, i \in I\right\}$ a family of non empty subsets of $X$ such as:

1- $\bigcup_{i \in I} S_{i}=X$

2- $\forall i \in I, \forall x \in S_{i}, \forall y \in S_{i}$, there exists a sequence $x_{0} \ldots x_{n}$ of elements of $X$ such as:

$x_{0}=x, x_{n}=y$ with $\forall j=0, \ldots, n-1, x_{j+1} \in a\left(\left\{x_{j}\right\}\right)$ or $x_{j} \in a\left(\left\{x_{j+1}\right\}\right)$

3- $\forall i \in I, \forall k \in I, i \neq k, \forall x \in S_{i}, \forall y \in S_{k}$, it does not exist a sequence $x_{0} \ldots x_{n}$ of elements of $X$ such as :

$x_{0}=x, x_{n}=y$ with $\forall j=0, \ldots, n-1, x_{j+1} \in a\left(\left\{x_{j}\right\}\right)$ or $x_{j} \in a\left(\left\{x_{j+1}\right\}\right)$

$i-\left\{S_{i}, i \in I\right\}$ is a partition of $X$.

$i i-\forall i \in I, S_{i}$ is a connected subspace of $(X, a)$.

Proof. i- By definition.

ii- $\forall \mathrm{i} \in \mathrm{I}, \mathrm{S}_{i}$ is a connected subspace of $(\mathrm{X}, a)$.

We can say $: \forall \mathrm{i} \in \mathrm{I}, \forall \mathrm{x} \in \mathrm{S}_{i}, \forall \mathrm{y} \in \mathrm{S}_{i}$, there exists a sequence $\mathrm{x}_{0} \ldots \mathrm{x}_{n}$ of elements of $\mathrm{X}$ such as $\mathrm{x}_{0}=\mathrm{x}, \mathrm{x}_{n}=\mathrm{y}$ with $\forall \mathrm{j}=0, \ldots, \mathrm{n}-1, \mathrm{x}_{j+1} \in \mathrm{a}\left(\left\{\mathrm{x}_{j}\right\}\right)$ or $\mathrm{x}_{j}$ $\in \mathrm{a}\left(\left\{\mathrm{x}_{j+1}\right\}\right)$ and $\forall \mathrm{i} \in \mathrm{I}, \forall \mathrm{k} \in \mathrm{I}, \mathrm{i} \neq \mathrm{k}, \forall \mathrm{x} \in \mathrm{S}_{i}, \forall \mathrm{y} \in \mathrm{S}_{k}$, it does not exist a sequence $\mathrm{x}_{0} \ldots \mathrm{x}_{n}$ of elements of $\mathrm{X}$ such as $\mathrm{x}_{0}=\mathrm{x}, \mathrm{x}_{n}=\mathrm{y}$ with $\forall \mathrm{j}=0, \ldots, \mathrm{n}-1$, $\mathrm{x}_{j+1} \in \mathrm{a}\left(\left\{\mathrm{x}_{j}\right\}\right)$ or $\mathrm{x}_{j} \in \mathrm{a}\left(\left\{\mathrm{x}_{j+1}\right\}\right)$

then, $\forall \mathrm{x} \in \mathrm{S}_{i}, \forall \mathrm{y} \in \mathrm{S}_{i}$, there exists a sequence $\mathrm{x}_{0} \ldots \mathrm{x}_{n}$ of elements of $\mathrm{S}_{i}$ such as $\mathrm{x}_{0}=\mathrm{x}, \mathrm{x}_{n}=\mathrm{y}$ with $\forall \mathrm{j}=0, \ldots, \mathrm{n}-1, \mathrm{x}_{j+1} \in \mathrm{a}\left(\left\{\mathrm{x}_{j}\right\}\right)$ or $\mathrm{x}_{j} \in \mathrm{a}\left(\left\{\mathrm{x}_{j+1}\right\}\right)$

because, otherwise there exists $\mathrm{x}_{j^{\prime}}$ element of $\mathrm{x}_{0} \ldots \mathrm{x}_{n}$ such as $\mathrm{x}_{j^{\prime}}$ does not belong to $\mathrm{S}_{i}$

then, there exists $\mathrm{k} \in \mathrm{I}$ such as $\mathrm{x}_{j^{\prime}} \in \mathrm{S}_{k}$ (from hypothesis 1 ) .

In this case, there exists a sequence $\mathrm{x}_{0} \ldots \mathrm{x}_{n}$ of elements of $\mathrm{X}$ such as 
$\mathrm{x}_{0}=\mathrm{x}, \mathrm{x}_{n}=\mathrm{x}_{j^{\prime}}$ with $\forall \mathrm{j}=0, \ldots, \mathrm{n}-1, \mathrm{x}_{j+1} \in \mathrm{a}\left(\left\{\mathrm{x}_{j}\right\}\right)$ or $\mathrm{x}_{j} \in \mathrm{a}\left(\left\{\mathrm{x}_{j+1}\right\}\right)$ which contradicts hypothesis 3 because $\mathrm{x} \in \mathrm{S}_{i}$ and $\mathrm{x}_{j^{\prime}} \in \mathrm{S}_{k}$.

At last, $\forall \mathrm{x} \in \mathrm{S}_{i}, \forall \mathrm{y} \in \mathrm{S}_{i}$, there exists a chain from $\{\mathrm{y}\}$ to $\{\mathrm{x}\}$ in $\left(\mathrm{S}_{i}, a_{S i}\right)$ (Property 2-i)

Which implies $\mathrm{S}_{i}$ is a connected subspace of (X,a) (Proposition 5-i) .

Proposition 10. Let $(X, a)$ be a $V_{s}$-type pretopological space. We assume the same conditions as in Proposition 9.

$i-\left\{S_{i}, i \in I\right\}$ is the set of connected components of $(X, a)$.

ii- $\left\{S_{i}, i \in I\right\}$ is the set of the greatest connected subspaces of $(X, a)$.

Proof. $\mathrm{i}-\forall \mathrm{i} \in \mathrm{I}, \mathrm{S}_{i}$ is a connected subspace of (X,a) (Proposition 9). Thus, $\mathrm{S}_{i}$ is a connected subset of $(\mathrm{X}, a)$ (Proposition 7-i) .

Let us prove that $\forall \mathrm{i} \in \mathrm{I}, \mathrm{S}_{i}=\mathrm{F}{ }_{a}\left(\mathrm{~S}_{i}\right)$ :

From Proposition 9 and Property 3 -i,

$\forall \mathrm{i} \in \mathrm{I}, \forall \mathrm{k} \in \mathrm{I}, \mathrm{i} \neq \mathrm{k}, \forall \mathrm{x} \in \mathrm{S}_{i}, \forall \mathrm{y} \in \mathrm{S}_{k}$, it does not exist a chain from $\{\mathrm{y}\}$ to $\{\mathrm{x}\}$ in $(\mathrm{X}, a)$

then $\forall \mathrm{i} \in \mathrm{I}, \forall \mathrm{k} \in \mathrm{I}, \mathrm{i} \neq \mathrm{k}, \forall \mathrm{x} \in \mathrm{S}_{i}, \forall \mathrm{y} \in \mathrm{S}_{k},\{\mathrm{y}\}$ is not included in $\mathrm{F}^{\prime \prime}(\{\mathrm{x}\})$

and $\forall \mathrm{x} \in \mathrm{S}_{i}, \mathrm{~S}_{i} \subset \mathrm{F}^{\prime \prime}{ }_{a}(\{\mathrm{x}\})=\mathrm{F}^{\prime}{ }_{a}(\mathrm{Si})$ (Property $\left.3-\mathrm{i}\right)$

then $\forall \mathrm{i} \in \mathrm{I}, \forall \mathrm{k} \in \mathrm{I}, \mathrm{i} \neq \mathrm{k}, \forall \mathrm{y} \in \mathrm{S}_{k},\{\mathrm{y}\}$ is not included in $\mathrm{F}^{\prime}{ }_{a}\left(\mathrm{~S}_{i}\right)$

which implies F" ${ }_{a}\left(\mathrm{~S}_{i}\right)=\mathrm{S}_{i}$

and leads to the result from Proposition 8.

ii- see [4].

Proposition 11. Let $(X, a)$ be a $V_{s}$-type pretopological space. We assume the same conditions as in Proposition 9.

Let $x \in X$ and $y \in X$. We get:

$i$ - There exists $i \in I, x \in S_{i}$ and $y \in S_{i} \Leftrightarrow x \in F^{\prime \prime}{ }_{a}(\{y\})$

ii- There exists $i \in I$, there exists $j \in I, i \neq j, x \in S_{i}$ and $y \in S_{j} \Leftrightarrow x \notin$ $F^{\prime \prime}{ }_{a}(\{y\})$.

Proof. i- and ii- From Property 3-i and Property 4.

\section{Decomposing $(X, a)$ with $a$ Idempotent for Strong Connectivity}

Proposition 12. Let $(X, a)$ be a $V$-type pretopological space with a idempotent. Let $x \in X$ and $y \in X$.

There exists a sequence $x_{0} \ldots x_{n}$ of elements of $X$ such as $x_{0}=x, x_{n}=y$ with $\forall j=0, \ldots, n-1, x_{j+1} \in a\left(\left\{x_{j}\right\}\right) \Leftrightarrow y \in a(\{x\})$. 
Proof. There exists a sequence $\mathrm{x}_{0} \ldots \mathrm{x}_{n}$ of elements of $\mathrm{X}$ such as $\mathrm{x}_{0}=\mathrm{x}, \mathrm{x}_{n}=\mathrm{y}$ with $\forall \mathrm{j}=0, \ldots, \mathrm{n}-1, \mathrm{x}_{j+1} \in a\left(\left\{\mathrm{x}_{j}\right\}\right)$ implies $\mathrm{y} \in a^{n}(\{\mathrm{x}\})$ hence $\mathrm{y} \in a(\{\mathrm{x}\})$ by idempotence of $a$.

Conversely: obvious.

Proposition 13. Let $(X, a)$ be a $V$-type pretopological space with a idempotent.

If $\left\{C_{i}, i \in I\right\}$ is a family of non empty subsets of $X$ such as:

1- $\bigcup_{i \in I} C_{i}=X$

2- $\forall i \in I, \forall x \in C_{i}, \forall y \in C_{i}$, there exists a sequence $x_{0} \ldots x_{n}$ of elements of $X$ such as $x_{0}=x, x_{n}=y$ with $\forall j=0, \ldots, n-1, x_{j+1} \in a\left(\left\{x_{j}\right\}\right)$

3- $\forall i \in I, \forall k \in I, i \neq k, \forall x \in C_{i}, \forall y \in C_{k}$, it does not exist a sequence $x_{0} \ldots x_{n}$ of elements of $X$ such as $x_{0}=x, x_{n}=y$ with $\forall j=0, \ldots, n-1, x_{j+1} \in$ $a\left(\left\{x_{j}\right\}\right)$ or it does not exist a sequence $x_{0} \ldots x_{n}$ of elements of $X$ such as $x_{0}=y$, $x_{n}=x$ with $\forall j=0, \ldots, n-1, x_{j+1} \in a\left(\left\{x_{j}\right\}\right)$

then for any $x \in X$ and $y \in X$.

$i$ - There exists $i \in I, x \in C_{i}$ and $y \in C_{i} \Leftrightarrow y \in a(\{x\})$ and $x \in a(\{y\})$.

ii- There exists $i \in I$, there exists $k \in I, i \neq k, x \in C_{i}$ and $y \in C_{k} \Leftrightarrow y$ $\notin a(\{x\})$ or $x \notin a(\{y\})$.

Proof. i- There exists $\mathrm{i} \in \mathrm{I}, \mathrm{x} \in \mathrm{C}_{i}$ and $\mathrm{y} \in \mathrm{C}_{i} \Leftrightarrow$ there exists a sequence $\mathrm{x}_{0} \ldots \mathrm{x}_{n}$ of elements of $\mathrm{X}$ such as $\mathrm{x}_{0}=\mathrm{x}, \mathrm{x}_{n}=\mathrm{y}$ with $\forall \mathrm{j}=0, \ldots, \mathrm{n}-1$, $\mathrm{x}_{j+1} \in a\left(\left\{\mathrm{x}_{j}\right\}\right)$

and there exists a sequence $\mathrm{x}_{0} \ldots \mathrm{x}_{n}$ of elements of $\mathrm{X}$ such as $\mathrm{x}_{0}=\mathrm{y}, \mathrm{x}_{n}=\mathrm{x}$ with $\forall \mathrm{j}=0, \ldots, \mathrm{n}-1, \mathrm{x}_{j+1} \in a\left(\left\{\mathrm{x}_{j}\right\}\right)$ (by definition of $\mathrm{C}_{i}$ )

which means that $\mathrm{y} \in a(\{\mathrm{x}\})$ and $\mathrm{x} \in a(\{\mathrm{y}\})$ (Proposition 12)

ii- By converse of $\mathrm{i}$.

Definition 9. Let $(\mathrm{X}, a)$ be a $\mathrm{V}$-type pretopological space. Let $\mathrm{A} \subset \mathrm{X}$ with A non empty.

i- $\mathrm{A}$ is a clique of $(\mathrm{X}, a)$ if and only if $\forall \mathrm{x} \in \mathrm{A}, \forall \mathrm{y} \in \mathrm{A}, \mathrm{y} \in a(\{\mathrm{x}\})$.

ii- $\mathrm{A}$ is a maximal clique of $(\mathrm{X}, a)$ if and only if $\mathrm{A}$ is a clique of $(\mathrm{X}, a)$ and $\forall \mathrm{A}^{\prime}, \mathrm{A} \subset \mathrm{A}^{\prime} \subset \mathrm{X}$ and $\mathrm{A} \neq \mathrm{A}^{\prime}, \mathrm{A}^{\prime}$ is not a clique of $(\mathrm{X}, a)$.

Proposition 14. Let $(X, a)$ be a $V$-type pretopological space with a idempotent.

Conditions are the same as in Proposition 13.

$\left\{C_{i}, i \in I\right\}$ is the set of maximal cliques of $(X, a)$.

Proof. Obvious from Proposition 13.

Proposition 15. Let $(X, a)$ be a $V$-type pretopological space with a idempotent. 
Conditions are the same as in Proposition 13.

$i$ - $\forall i \in I, C_{i}$ is greatest strongly connected subspace of $(X, a)$.

$i i-\forall i \in I, C_{i}$ is a strongly connected component of $(X, a)$.

Proof. $\mathrm{i}-\mathrm{C}_{i}$ is strongly connected subspace of (X, a) (Proposition 13 and Proposition 5-ii) . Let us prove that $\mathrm{C}_{i}$ is greatest strongly connected subspace of $(\mathrm{X}, a)$ :

If not, there exists $\mathrm{A}$ such as $\mathrm{C}_{i} \subset \mathrm{A} \subset \mathrm{X}$ and $\mathrm{C}_{i} \neq \mathrm{A}$ and $\mathrm{A}$ is greatest strongly connected subspace of $(\mathrm{X}, a)$ with $\mathrm{A}=\bigcup_{j \in J_{A}} C_{j}\left(\mathrm{~J}_{A} \subset \mathrm{I}\right)$ and $\mathrm{F}_{a A}\left(\mathrm{C}_{j}\right)$ $=\mathrm{A}, \forall \mathrm{j} \in \mathrm{J}_{A}($ see $[4])$.

But $\mathrm{F}_{a A}=a_{A}$ (Proposition 4-i)

then $\forall \mathrm{j} \in \mathrm{J}_{A}, a_{A}\left(\mathrm{C}_{j}\right)=a\left(\mathrm{C}_{j}\right) \cap \mathrm{A}=\mathrm{A}$.

In particular, $a\left(\mathrm{C}_{i}\right) \cap \mathrm{A}=\mathrm{A}$

then $\mathrm{A} \subset a\left(\mathrm{C}_{i}\right)$

then if $\mathrm{C}_{j} \subset \mathrm{A}$ with $\mathrm{i} \neq \mathrm{j}$, we get $\mathrm{C}_{j} \subset a\left(\mathrm{C}_{i}\right)$

hence $\forall \mathrm{x} \in \mathrm{C}_{j}, \forall \mathrm{y} \in \mathrm{C}_{i}, \mathrm{x} \in a(\{\mathrm{y}\})$ (because $\left.a(\{\mathrm{y}\})=a\left(\mathrm{C}_{i}\right)\right)$.

From Proposition 13-ii, we can say $\forall \mathrm{x} \in \mathrm{C}_{j}, \forall \mathrm{y} \in \mathrm{C}_{i}, \mathrm{y} \notin a(\{\mathrm{x}\})=a\left(\mathrm{C}_{j}\right)$ then $a\left(\mathrm{C}_{j}\right) \cap \mathrm{A} \neq \mathrm{A}$

which contredicts A greatest strongly connected subspace of (X,a).

That means $\mathrm{C}_{i}$ is greatest strongly connected subspace of $(\mathrm{X}, a)$.

ii- From Proposition 7-ii.

Consequence: In a V-type pretopological space with a idempotent, in particular in the usual topological, maximal cliques provide the greatest strongly connected subspaces which also are the strongly connected components.

\section{Decomposing $(X, a)$ with $a$ Idempotent for Connectivity}

Proposition 16. Let $(X, a)$ be a $V_{s}$-type pretopological space with a idempotent.

Let $A \subset X . F^{\prime \prime}{ }_{a}(A)=\bigcup_{n \geq 0}\left(a^{\prime} a\right)^{n}(A)$.

Proof. Let $\mathrm{A} \subset \mathrm{X}, \mathrm{F}^{\prime \prime}{ }_{a}(\mathrm{~A})=\bigcup_{n \geq 0}\left(F_{a}^{\prime} F_{a}\right)^{n}(A)$ (see [5]).

$=\bigcup_{n \geq 0}\left(a^{\prime} a\right)^{n}(A)$ (from Propositions 1 and 3 ).

Proposition 17. Let $(X, a)$ be a $V_{s}$-type pretopological space with a idempotent.

Conditions are the same as in Proposition 9.

For any $x \in X$ and $y \in X$. 
$i$ - There exists $i \in I, x \in S_{i}$ and $y \in S_{i} \Leftrightarrow x \in \bigcup_{n \geq 0}\left(a^{\prime} a\right)^{n}(\{y\})$.

ii- There exists $i \in I$, there exists $k \in I, i \neq k, x \in S_{i}$ and $y \in S_{k} \Leftrightarrow x$ $\notin \bigcup_{n \geq 0}\left(a^{\prime} a\right)^{n}(\{y\})$.

Proof. i- and ii- From Proposition 11 and Proposition 16.

\section{Application for Pretopology of Collateral}

Remark 2. $\forall x \in X, \forall z \in X$ with $x \neq z$,

- If $R^{-1}(x) \neq \varnothing$ then $x \in a_{c}(\{z\}) \Leftrightarrow R^{-1}(x) \subset R^{-1}(z)$

- If $R^{-1}(x)=\varnothing$ then $x \notin a_{c}(\{z\})$.

Proof. $a_{c}(\{\mathrm{z}\})=\left\{\mathrm{x} \in \mathrm{X} / \forall \mathrm{y} \in \mathrm{R}^{-1}(\mathrm{x}), \mathrm{R}(\mathrm{y}) \cap\{\mathrm{z}\} \neq \varnothing\right\} \cup\{\mathrm{z}\}=\{\mathrm{x} \in \mathrm{X} / \forall \mathrm{y}$ $\left.\in \mathrm{R}^{-1}(\mathrm{x}), \mathrm{z} \in \mathrm{R}(\mathrm{y})\right\} \cup\{\mathrm{z}\}$

- If $\mathrm{R}^{-1}(\mathrm{x})=\varnothing$ then $\mathrm{x} \notin a_{c}(\{\mathrm{z}\})$ by definition.

- If $\mathrm{R}^{-1}(\mathrm{x}) \neq \varnothing$

then $\mathrm{x} \in a_{c}(\{\mathrm{z}\}) \Leftrightarrow \forall \mathrm{y} \in \mathrm{R}^{-1}(\mathrm{x}), \mathrm{z} \in \mathrm{R}(\mathrm{y})$

$\Leftrightarrow \forall \mathrm{y} \in \mathrm{R}^{-1}(\mathrm{x}), \mathrm{y} \in \mathrm{R}^{-1}(\mathrm{z})$

$\Leftrightarrow \mathrm{R}^{-1}(\mathrm{x}) \subset \mathrm{R}^{-1}(\mathrm{z})$

Remark 3. $a_{c}$ is idempotent.

Proof. Let us prove that $\forall \mathrm{A} \subset \mathrm{X}, a_{c}\left(a_{c}(\mathrm{~A})\right)=a_{c}(\mathrm{~A})$ :

$a_{c}(\mathrm{~A})=\left\{\mathrm{x} \in \mathrm{X} / \forall \mathrm{y} \in \mathrm{R}^{-1}(\mathrm{x}), \mathrm{R}(\mathrm{y}) \cap \mathrm{A} \neq \varnothing\right\} \cup \mathrm{A}$

then $a_{c}\left(a_{c}(\mathrm{~A})\right)=a_{c}(\mathrm{~A}) \cup\left\{\mathrm{x} \in \mathrm{X} / \forall \mathrm{y} \in \mathrm{R}^{-1}(\mathrm{x}), \mathrm{R}(\mathrm{y}) \cap a_{c}(\mathrm{~A}) \neq \varnothing\right\}$.

If $\mathrm{x} \in a_{c}\left(a_{c}(\mathrm{~A})\right)$ and $\mathrm{x} \notin a_{c}(\mathrm{~A})$

then $\forall \mathrm{y} \in \mathrm{R}^{-1}(\mathrm{x}), \mathrm{R}(\mathrm{y}) \cap a_{c}(\mathrm{~A}) \neq \varnothing$ and there exists $\mathrm{y} \in \mathrm{R}^{-1}(\mathrm{x}), \mathrm{R}(\mathrm{y}) \cap \mathrm{A}$ $=\varnothing$ and $\mathrm{x} \notin \mathrm{A}$

then $\forall \mathrm{y} \in \mathrm{R}^{-1}(\mathrm{x})$ such as $\mathrm{R}(\mathrm{y}) \cap \mathrm{A}=\varnothing$, we get:

there exists $\mathrm{y}^{\prime}$ such as $\mathrm{y}^{\prime} \notin \mathrm{A}, \mathrm{y}^{\prime} \in \mathrm{R}(\mathrm{y})$ and $\mathrm{y}^{\prime} \in a_{c}(\mathrm{~A})$

then there exists y' such as $\mathrm{y}^{\prime} \notin \mathrm{A}, \mathrm{y}^{\prime} \in \mathrm{R}(\mathrm{y})$ and $\forall \mathrm{y}^{\prime \prime} \in \mathrm{R}^{-1}\left(\mathrm{y}^{\prime}\right), \mathrm{R}\left(\mathrm{y}{ }^{\prime \prime}\right) \cap \mathrm{A}$ $\neq \varnothing$

then there exists $\mathrm{y}^{\prime}$ such as $\mathrm{y}^{\prime} \notin \mathrm{A}, \mathrm{y} \in \mathrm{R}^{-1}\left(\mathrm{y}^{\prime}\right)$ and $\forall \mathrm{y}^{\prime \prime} \in \mathrm{R}^{-1}\left(\mathrm{y}^{\prime}\right)$, $\mathrm{R}(\mathrm{y} ") \cap \mathrm{A} \neq \varnothing$

Which implies $\mathrm{R}(\mathrm{y}) \cap \mathrm{A} \neq \varnothing$; Not possible.

Remark 4. For any $x \in X$ and $y \in X$.

Following assertions are equivalent:

$i-y \in a_{c}(\{x\})$ 
ii- There exists a sequence $x_{0} \ldots x_{n}$ of elements of $X$ such as $x_{0}=x, x_{n}=y$ with $\forall j=0, \ldots, n-1, x_{j+1} \in a_{c}\left(\left\{x_{j}\right\}\right)$

iii- $R^{-1}(y) \subset R^{-1}(x)$ with $R^{-1}(y) \neq \varnothing$ or $x=y$.

Proof. From Remarks 2 and 3 and from Proposition 12.

Proposition 18. Let $\left(X, a_{c}\right)$ a pretopological space with $a_{c}$ collateral pretopology.

Conditions are the same as in Proposition 13.

For any $x \in X$ and $y \in X$.

$i$ - 1 - There exists $i \in I, x \in C_{i}$ and $y \in C_{i} \Leftrightarrow x=y$ or $\left(R^{-1}(y) \neq \varnothing\right.$ and $R^{-1}(x) \neq \varnothing$ with $\left.R^{-1}(x)=R^{-1}(y)\right)$.

2- There exists $i \in I$, there exists $k \in I, i \neq k, x \in C_{i}$ and $y \in C_{k} \Leftrightarrow$ $x \neq y$ and $\left(R^{-1}(y)=\varnothing\right.$ or $R^{-1}(x)=\varnothing \quad$ or $\left(R^{-1}(x) \neq \varnothing\right.$ and $R^{-1}(y) \neq \varnothing$ with $\left.\left.R^{-1}(x) \neq R^{-1}(y)\right)\right)$.

$i i-\left\{C_{i}, i \in I\right\}$ is the set of the greatest strongly connected subspaces of $(X, a)$ and also the set of maximal cliques of $(X, a)$.

Proof. i- 1- There exists $\mathrm{i} \in \mathrm{I}, \mathrm{x} \in \mathrm{C}_{i}$ and $\mathrm{y} \in \mathrm{C}_{i}$

$\Leftrightarrow \mathrm{y} \in a_{c}(\{\mathrm{x}\})$ and $\mathrm{x} \in a_{c}(\{\mathrm{y}\})$ (Proposition 13)

$\Leftrightarrow\left(\mathrm{R}^{-1}(\mathrm{y}) \subset \mathrm{R}^{-1}(\mathrm{x})\right.$ with $\mathrm{R}^{-1}(\mathrm{y}) \neq \varnothing$ or $\left.\mathrm{x}=\mathrm{y}\right)$

and $\left(\mathrm{R}^{-1}(\mathrm{x}) \subset \mathrm{R}^{-1}(\mathrm{y})\right.$ with $\mathrm{R}^{-1}(\mathrm{x}) \neq \varnothing$ or $\left.\mathrm{x}=\mathrm{y}\right)($ Remark 4$)$

$\Leftrightarrow\left(\mathrm{R}^{-1}(\mathrm{y}) \subset \mathrm{R}^{-1}(\mathrm{x})\right.$ and $\mathrm{R}^{-1}(\mathrm{x}) \subset \mathrm{R}^{-1}(\mathrm{y})$ with $\mathrm{R}^{-1}(\mathrm{x}) \neq \varnothing$ and $\mathrm{R}^{-1}(\mathrm{y})$ $\neq \varnothing)$ or $(\mathrm{x}=\mathrm{y})$

$\Leftrightarrow\left(\mathrm{R}^{-1}(\mathrm{y})=\mathrm{R}^{-1}(\mathrm{x})\right.$ with $\mathrm{R}^{-1}(\mathrm{x}) \neq \varnothing$ and $\left.\mathrm{R}^{-1}(\mathrm{y}) \neq \varnothing\right)$ or $(\mathrm{x}=\mathrm{y})$.

2- By converse of i-1.

ii- From Propositions 14 and 15.

Proposition 19. Let $\left(X, a_{c}\right)$ a pretopological space with ac collateral pretopology.

Let $x \in X$.

Let $C(x)$ greatest strongly connected subspace of $(X, a)$ including $x$.

If $R^{-1}(x) \neq \varnothing, C(x)=\left\{y \in X / R^{-1}(x)=R^{-1}(y)\right\}$.

If $R^{-1}(x)=\varnothing, C(x)=\{x\}$.

Proof. From Proposition 18.

Example. Let $\left(X, a_{c}\right)$ a pretopological space with $X=\{a, b, c, d, e, f, g, h, i, j\}$ and $a_{c}$ collateral pretopology defined according to data in the following table: 


\begin{tabular}{|c|c|c|}
\hline $\mathrm{x}$ & $\mathrm{R}^{-1}(\mathrm{x})$ & $\mathrm{C}(\mathrm{x})$ \\
\hline $\mathrm{a}$ & $\{\mathrm{e}, \mathrm{f}, \mathrm{g}\}$ & $\{\mathrm{a}, \mathrm{b}\}$ \\
\hline $\mathrm{b}$ & $\{\mathrm{e}, \mathrm{f}, \mathrm{g}\}$ & $\{\mathrm{a}, \mathrm{b}\}$ \\
\hline $\mathrm{c}$ & $\{\mathrm{g}, \mathrm{h}\}$ & $\{\mathrm{c}, \mathrm{d}\}$ \\
\hline $\mathrm{d}$ & $\{\mathrm{g}, \mathrm{h}\}$ & $\{\mathrm{c}, \mathrm{d}\}$ \\
\hline $\mathrm{e}$ & $\varnothing$ & $\{\mathrm{e}\}$ \\
\hline $\mathrm{f}$ & $\varnothing$ & $\{\mathrm{f}\}$ \\
\hline $\mathrm{g}$ & $\{\mathrm{i}\}$ & $\{\mathrm{g}, \mathrm{h}\}$ \\
\hline $\mathrm{h}$ & $\{\mathrm{i}\}$ & $\{\mathrm{g}, \mathrm{h}\}$ \\
\hline $\mathrm{i}$ & $\varnothing$ & $\{\mathrm{i}\}$ \\
\hline $\mathrm{j}$ & $\{\mathrm{e}\}$ & $\{\mathrm{j}\}$ \\
\hline
\end{tabular}

Then, we get 7 greatest strongly connected subspaces (or strongly connected components) or maximal cliques : $C(a)=\{a, b\}, C(d)=\{c, d\}, C(e)=\{e\}$, $C(f)=\{f\}, C(g)=\{g, h\}, C(i)=\{i\}, C(j)=\{j\}$.

\section{Application Starting from a Transitive Binary Relationship}

Let $\mathrm{X}$ a non empty set and $R$ a binary relationship defined on $\mathrm{X}$. The pretopology of successors, noted $a_{d}$, is defined by the following pseudoclosure:

$$
\begin{gathered}
\forall \mathrm{A} \subset \mathrm{X}, a_{d}(\mathrm{~A})=\{\mathrm{x} \in \mathrm{X} / R(\mathrm{x}) \cap \mathrm{A} \neq \varnothing\} \cup \mathrm{A} \\
\text { with } R(\mathrm{x})=\{\mathrm{y} \in \mathrm{X} / \mathrm{x} R \mathrm{y}\}
\end{gathered}
$$

The pretopology of antecedents, noted $a_{a}$, is defined by:

$\forall \mathrm{A} \subset \mathrm{X}, a_{a}(\mathrm{~A})=\left\{\mathrm{x} \in \mathrm{X} / R^{-1}(\mathrm{x}) \cap \mathrm{A} \neq \varnothing\right\} \cup \mathrm{A}$ with $R^{-1}(\mathrm{x})=\{\mathrm{y} \in \mathrm{X} /$ $\mathrm{y} R \mathrm{x}\}$.

Let $R$ a transitive binary relationship and $\left(\mathrm{X}, a_{d}\right)$ the pretopological space of successors defined from $R$. In this case, $a_{d}$ is of a $\mathrm{V}_{s}$-type and also idempotent (because of transitivity of $\mathrm{R}$ ).

We also can say that $\left(a_{d}\right)^{\prime}=\left(\left(a_{a}\right)^{\prime}\right)^{\prime}=a_{a}$ (see [8]).

Example. Let $\left(X, a_{d}\right)$ the pretopological space of successors, with $X=$ $\{a, b, c, d, e, f, g\}$, defined according to data in the following table: 


\begin{tabular}{|c|c|}
\hline$x$ & $R(x)$ \\
\hline$a$ & $\{a, b, c, d\}$ \\
\hline$b$ & $\{a, b, c, d\}$ \\
\hline$c$ & $\{a, b, c, d\}$ \\
\hline$d$ & $\{a, b, c, d\}$ \\
\hline$e$ & $\{a, b, c, d, e\}$ \\
\hline$f$ & $\{f, g\}$ \\
\hline$g$ & $\{f, g\}$ \\
\hline
\end{tabular}

$C_{1}=\{a, b, c, d\}, C_{2}=\{e\}$ and $C_{3}=\{f, g\}$ are the maximal cliques or also the greatest strongly connected subspaces (or strongly connected components). $S_{1}=\{a, b, c, d, e\}$ and $S_{2}=\{f, g\}$ are the greatest connected subspaces (or connected components).

\section{References}

[1] Z. Belmandt, Manuel de prétopologie et ses applications, Hermès, Paris (1993).

[2] M. Brissaud, Chaînes et connexités, Seminar URA 934, Villeurbanne (1990).

[3] M. Dalud-Vincent, Modèle prétopologique pour une méthodologie d'analyse de réseaux. Concepts et algorithmes, Ph.D. Thesis, Lyon 1 University (1994).

[4] M. Dalud-Vincent, M. Brissaud, M. Lamure, Pretopology as an extension of graph theory: the case of strong connectivity, International Journal of Applied Mathematics, 5, $\mathrm{N}^{\circ} 4$ (2001), 455-472.

[5] M. Dalud-Vincent, M. Brissaud, M. Lamure, Closed sets and closures in pretopology, International Journal of Pure and Applied Mathematics, 50, No. 3 (2009), 391-402.

[6] M. Dalud-Vincent, M. Brissaud, M. Lamure, Pretopology, Matroïdes and Hypergraphs, International Journal of Pure and Applied Mathematics, 67, No. 4 (2011), 363-375.

[7] M. Dalud-Vincent, M. Brissaud, M. Lamure, Connectivities and Partitions in a Pretopological Space, International Mathematical Forum, 6, No. 45 (2011), 2201-2215.

[8] M. Dalud-Vincent, M. Lamure, Connectivities for a Pretopology and its inverse, International Journal of Pure and Applied Mathematics, 86, No. 1 (2013), 43-54. http://dx.doi.org/10.12732/ijpam.v86i1.5.

[9] G. Duru, Contribution à l'étude des structures des systèmes complexes dans les sciences humaines, Thèse d'Etat, Lyon I (1980). 